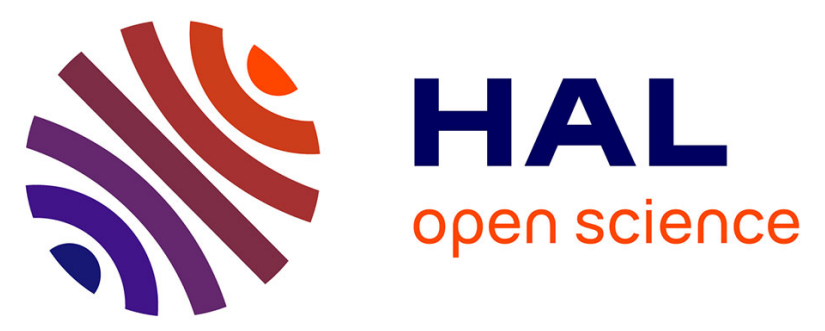

\title{
Full Antibody Primary Structure and Microvariant Characterization in a Single Injection Using Transient Isotachophoresis and Sheathless Capillary Electrophoresis-Tandem Mass Spectrometry
}

Rabah Gahoual, Jean-Marc Busnel, Alain Beck, Yannis-Nicolas François, Emmanuelle Leize-Wagner

\section{To cite this version:}

Rabah Gahoual, Jean-Marc Busnel, Alain Beck, Yannis-Nicolas François, Emmanuelle Leize-Wagner. Full Antibody Primary Structure and Microvariant Characterization in a Single Injection Using Transient Isotachophoresis and Sheathless Capillary Electrophoresis-Tandem Mass Spectrometry. Analytical Chemistry, 2014, 86 (18), pp.9074-9081. 10.1021/ac502378e . hal-01981311

\author{
HAL Id: hal-01981311 \\ https://hal.science/hal-01981311
}

Submitted on 14 Jan 2019

HAL is a multi-disciplinary open access archive for the deposit and dissemination of scientific research documents, whether they are published or not. The documents may come from teaching and research institutions in France or abroad, or from public or private research centers.
L'archive ouverte pluridisciplinaire HAL, est destinée au dépôt et à la diffusion de documents scientifiques de niveau recherche, publiés ou non, émanant des établissements d'enseignement et de recherche français ou étrangers, des laboratoires publics ou privés. 


\title{
Full Antibody Primary Structure and Microvariant Characterization in a Single Injection Using Transient Isotachophoresis and Sheathless ${ }_{3}$ Capillary Electrophoresis-Tandem Mass Spectrometry
}

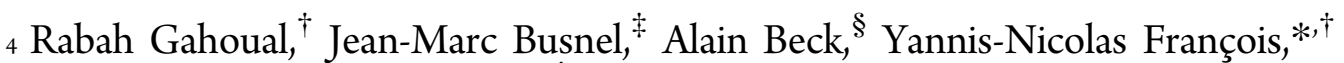 \\ $s$ and Emmanuelle Leize-Wagner ${ }^{\dagger}$ \\ $6{ }^{\dagger}$ Laboratoire de Spectrométrie de Masse des Interactions et des Systèmes (LSMIS), UDS-CNRS UMR 7140, Université de \\ 7 Strasbourg, Strasbourg, France \\ 8 "Beckman Coulter Inc., Marseille, France \\ $9{ }^{\S}$ Centre d'immunologie Pierre Fabre, Saint-Julien-en-Genevois, France
}

10

Supporting Information

11 ABSTRACT: Here we report the complete characterization of the primary structure of a multimeric glycoprotein in a single analysis by capillary electrophoresis (CE) coupled to mass spectrometry (MS). CE was coupled to electrospray ionization tandem MS by means of a sheathless interface. Transient isotachophoresis ( $t$-ITP) was introduced in this work as an electrokinetically based preconcentration technique, allowing injection of up to $25 \%$ of the total capillary volume. Characterization was based on an adapted bottom-up proteomic strategy. Using trypsin as the sole proteolytic enzyme and data from a single injection per considered protein, $100 \%$ of the amino acid sequences of four different monoclonal antibodies could be achieved. Furthermore, illustrating the effectiveness and overall capabilities of the technique, the results were possible through identification of peptides without tryptic miscleavages or posttranslational modifications, demonstrating the potency of the technique. In addition to full sequence coverages, posttranslational modifications (PTMs) were simultaneously identified, further demonstrating the capacity of this strategy to structurally characterize glycosylations as well as faint modifications such as asparagine deamidation or aspartic acid isomerization. Together with the exquisite detection sensitivity observed, the contributions of both the CE separation mechanism and selectivity were essential to the result of the characterization with regard to that achieved with conventional MS strategies. The quality of the results indicates that recent improvements in interfacing CE-MS coupling, leading to a considerably improved sensitivity, allows characterization of the primary structure of proteins in a robust and faster manner. Taken together, these results open new research avenues for characterization of proteins through MS.

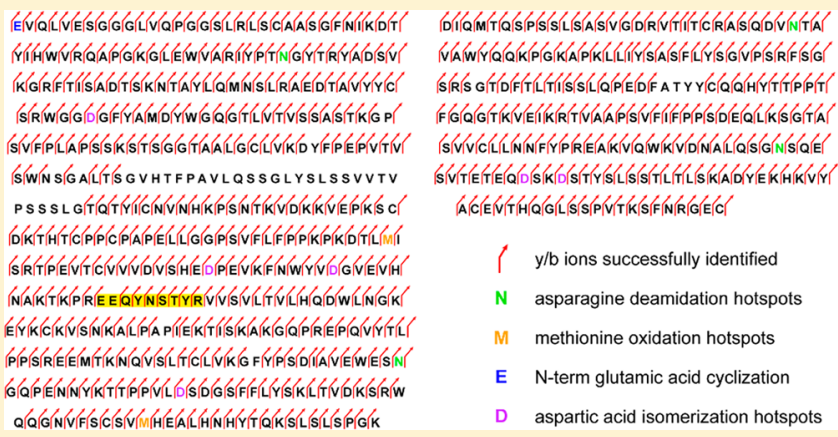

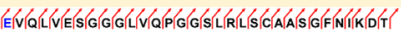

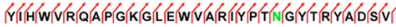

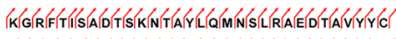

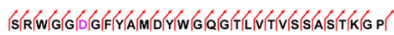

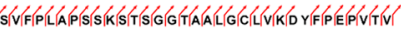

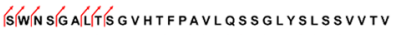

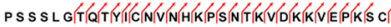

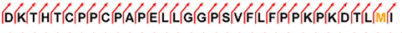

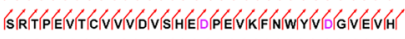

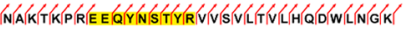

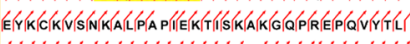

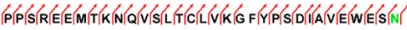

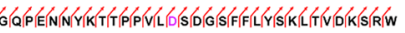

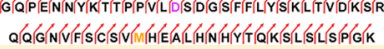

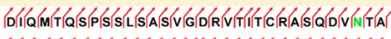

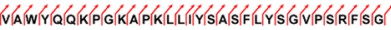

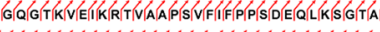

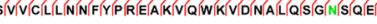

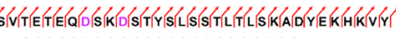

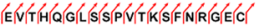

$y / b$ ions successfully identified

M methionine oxidation hotspots

$\mathrm{N}$-term glutamic acid cyclizatio ts

33 apillary electrophoresis (CE) was commercially intro$34-$ duced as a separation technique during the early $351980 \mathrm{~s}^{1-3}$ though electrokinetically driven separation strategies 36 have been applied in laboratories since the beginning of the 37 20th century. ${ }^{4,5}$ In CE, analytes are separated under an 38 electrical field; this technique has some major advantages 39 including the possibility to obtain separations within minutes 40 while maintaining exceptional separation efficiency. This is 41 partially explained by the absence of a stationary phase, 42 tremendously reducing the longitudinal dispersion responsible 43 for peak broadening. Despite the considerable effort made 44 regarding instrumental development, platforms combining $\mathrm{CE}$ 45 and electrospray ionization (ESI) mass spectrometry (MS) are 46 still marginally used as compared to chromatography-based 47 methods. This is mainly related to the difficulty to maintain the $48 \mathrm{CE}$ electrical field while positioning the capillary outlet inside 49 the ESI source. Another aspect is related to the fact that CE-

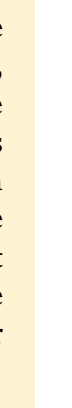

ESI-MS platforms rarely provide optimal sensitivity, as 50 common interfaces rely on strategies that by nature induce 51 losses of sensitivity. ${ }^{6,7}$ On the other hand, coupling of high- 52 performance liquid chromatography (HPLC) with MS is more 53 straightforward and tends to be preferentially used for 54 separation ahead of MS due to its ease of coupling and 55 excellent robustness. However, as ESI-MS has demonstrated its 56 suitability for the study of biological samples such as protein 57 and peptides, ${ }^{8,9}$ electrophoresis should be theoretically the 58 preferred separation technique for biological samples especially 59 because it is a miniaturized technique which should favor the 60 formation of a nanoESI, thus enhancing the ionization process. 61 Biologists are routinely using electrophoresis to reduce the 62

Received: $\quad$ May 7, 2014

Accepted: August 20, 2014 
63 complexity of samples or to isolate proteins ${ }^{10}$ and likewise 64 DNA $^{11,12}$ or RNA. ${ }^{13,14}$ Recently a novel sheathless interface 65 was introduced for CE-ESI-MS hyphenation. ${ }^{15}$ It is originally 66 based on a sheathless design by Moini et al. ${ }^{16}$ and is here 67 referred to as CESI-MS. It allows the hyphenation of CE to 68 ESI-MS without sacrificing the sensitivity because it does not 69 require any sheath liquid to maintain the electrical contact, 70 which would otherwise be responsible for analyte dilution. 71 Separation performances and characteristics of CE are in terms 72 of efficiency and selectivity, well applicable to the range of 73 analytes that are typically well separated by reverse phase liquid 74 chromatography (RP-LC). Additionally, CE could also alleviate 75 some of the drawbacks usually encountered when using RP-LC 76 such as separation and elution of very small and hydrophilic 77 peptides that may elute with the dead volume in RP-LC or 78 large ones that could be adsorbed irreversibly on the stationary 79 phase. Other groups have recently shown that the implementa80 tion of an electrophoretic separation, prior to the MS analysis, 81 could benefit bottom-up proteomics analysis compared to 82 conventional methodologies. ${ }^{17,18}$ Here we are reporting the 83 capacity of t-ITP CESI-MS/MS methodology to enable the 84 complete amino acid (AA) sequence characterization for a 85 protein in a single injection. Transient isotachophoresis (t-ITP) 86 is an electrokinetic-based preconcentration process, commonly 87 used in CZE, which allows for larger sample injections without 88 any detrimental effect on separation efficiency. Contrarily, the 89 integration of t-ITP often enables an improvement of 90 separation efficiency as compared to conventional CZE. ${ }^{19}$ In $91 \mathrm{t}$-ITP, the sample buffer used has an electrophoretic mobility 92 superior to that of the background electrolyte (BGE); under 93 the electrical field applied during the separation, the sample 94 content is stacked in a reduced capillary volume compared to 95 the actual injected volume. The use of t-ITP allows for the 96 injection of significantly larger volumes without losing 97 separation efficiency: maximum of $25 \%$ of the total capillary 98 volume while only $1-2 \%$ in conventional CZE. ${ }^{15}$

$99 \mathrm{mAbs}$ (monoclonal antibodies) are tetrameric glycoproteins 100 having a molecular mass of approximately $150 \mathrm{kDa}$. They are 101 composed of two heavy chains (HCs) and two light chains 102 (LCs) linked to each other by several disulfide bonds. The HC 103 bears at least one $\mathrm{N}$-glycosylation site. ${ }^{20}$ The first monoclonal 104 antibody $(\mathrm{mAb})$ studied here was trastuzumab, which is 105 approved for the treatment of HER2-positive breast cancer, ${ }^{21}$ 106 and the second antibody studied was cetuximab, directed 107 against epidermal growth factor receptor (EGFR) and used to 108 treat colorectal, head, and neck cancer. ${ }^{22,23}$ From an analytical 109 standpoint, these proteins have an interesting trait due to their 110 structural complexity. They present a large number of 111 microheterogeneities commonly found in proteins such as 112 posttranslational modifications (PTMs) including glycosyla113 tions and small chemical modifications. ${ }^{24}$ Four mAbs were 114 studied. Along with the characterization of the AA sequence, 115 other aspects of the primary structure of the studied proteins 116 could be characterized with an unprecedented reliability. 117 Separation mechanisms provided by CE demonstrated their 118 utility for protein characterization by MS, as it has been 119 possible to separate peptides having only minor differences as 120 small as one AA conformational change.

\section{EXPERIMENTAL SECTION}

122 Materials. Chemicals used were of analytical grade or high 123 purity grade and purchased from Sigma-Aldrich (Saint Louis, $124 \mathrm{MO}$ ). Water used to prepare buffers and sample solutions was obtained using an ELGA Purelab UHQ PS water purification 125 system (Bucks, UK). Trastuzumab and cetuximab samples are 126 EMA/FDA-approved formulations purchased, respectively, 127 from Genentech (San Francisco, CA) and Merck (Whitehouse 128 Station, NJ). RapiGest SF surfactant was purchased from 129 Waters (Milford, MA).

130

Sample Preparation. For each mAb sample, a volume 131 corresponding to $100 \mu \mathrm{g}$ of protein was sampled using the final 132 formulation for the approved mAbs (trastuzumab and 133 cetuximab) and samples coming directly from the bioreactor 134 for the mAbs in development samples. Samples were diluted 135 using Milli-Q water to a final concentration of $6.7 \mu \mathrm{g} / \mu \mathrm{L} .136$ Samples were then diluted using $0.1 \%$ RapiGest surfactant to a 137 final concentration of $3.35 \mu \mathrm{g} / \mu \mathrm{L}$ and heated to $40{ }^{\circ} \mathrm{C}$ during 138 $10 \mathrm{~min}$. Dithiothreitol (DTT) was added to the sample to 139 obtain a final concentration of $25 \mathrm{mM}$. Samples were then 140 heated to $95{ }^{\circ} \mathrm{C}$ during $5 \mathrm{~min}$. After the sample was cooled to 141 room temperature (RT), iodoacetamide (IDA) was added to a 142 final concentration of $10 \mathrm{mM}$. Afterward, samples were placed 143 in the dark for 20 min to allow alkylation of cysteine (Cys). A 144 volume of $1 \mu \mathrm{L}$ of trypsin $(0.5 \mu \mathrm{g} / \mu \mathrm{L})$ was added to the 145 sample, which was left at room temperature for $3 \mathrm{~h}$, and 146 another volume of $1 \mu \mathrm{L}$ was added afterward. Digestion was 147 performed overnight at $37{ }^{\circ} \mathrm{C}$. After digestion was complete, 148 formic acid (FA) was added to the samples at a final 149 concentration of $1 \%(\mathrm{v} / \mathrm{v})$ to cleave the surfactant, and samples 150 were left at RT for $2 \mathrm{~h}$. Finally, samples were diluted to a final 151 protein concentration of $2.2 \mu \mathrm{M}$ using $50 \mathrm{mM}$ ammonium 152 acetate ( $\mathrm{pH} 4.0)$.

Capillary Electrophoresis. The CE experiments were 154 performed with a PA 800 Plus capillary electrophoresis system 155 from Beckman Coulter equipped with a temperature-controlled 156 autosampler and a power supply able to deliver up to $30 \mathrm{kV} \cdot 157$ Hyphenation was realized using a CESI prototype made 158 available by Sciex Separations (Brea, CA). The prototype of 159 bare fused-silica capillaries (total length $100 \mathrm{~cm}$; $30 \mu \mathrm{m}$ i.d.) 160 had a characteristic porous tip of $3 \mathrm{~cm}$ on the end, and a second 161 capillary (total length $80 \mathrm{~cm} ; 50 \mu \mathrm{m}$ i.d.) filled during 162 experiments with BGE allows electric contact. The new 163 capillaries were flushed for $10 \mathrm{~min}$ at $75 \mathrm{psi}$ (5.17 bar) with 164 methanol and then $10 \mathrm{~min}$ with $0.1 \mathrm{M}$ sodium hydroxide, 165 followed by $10 \mathrm{~min}$ with $0.1 \mathrm{M}$ hydrochloric acid and $20 \mathrm{~min} 166$ with water also at 75 psi. Finally, the capillary was flushed 10167 min at 75 psi with BGE which was $10 \%$ acetic acid. 168 Hydrodynamic injection (410 mbar for $1 \mathrm{~min}$ ) corresponding 169 to a total volume of $90 \mathrm{~nL}$ of sample injected was used. 170 Separations were performed using a voltage of $+20 \mathrm{kV}$. 171

Mass Spectrometry. For antibody characterization, the 172 CESI system was hyphenated to a 5600 TripleTOF mass 173 spectrometer (AB Sciex, Darmstadt, Germany). The 5600 MS 174 was equipped with a hybrid analyzer composed of quadrupoles 175 followed by a time-of-flight (TOF) analyzer. ESI source 176 parameters were set as follows: ESI voltage $-1.75 \mathrm{kV}$ while 177 gas supplies (GS1 and GS2) were deactivated, source heating 178 temperature $150^{\circ} \mathrm{C}$, and curtain gas value 5. Experiments were 179 performed in Top15 information-dependent acquisition (IDA), 180 and accumulation time was $250 \mathrm{~ms}$ for MS scans and $100 \mathrm{~ms} 181$ for MS/MS scans, leading to a total duty cycle of $1.75 \mathrm{~s}$. Mass/ 182 charge $(\mathrm{m} / \mathrm{z})$ range was 100-2000 in MS and 50-2000 in MS/ 183 MS. Using those parameters, the mean resolution provided by 184 the instrument was 40000 in MS $(m / z 485.251)$ and 25000 in 185 MS/MS ( $m / z$ 345.235). 


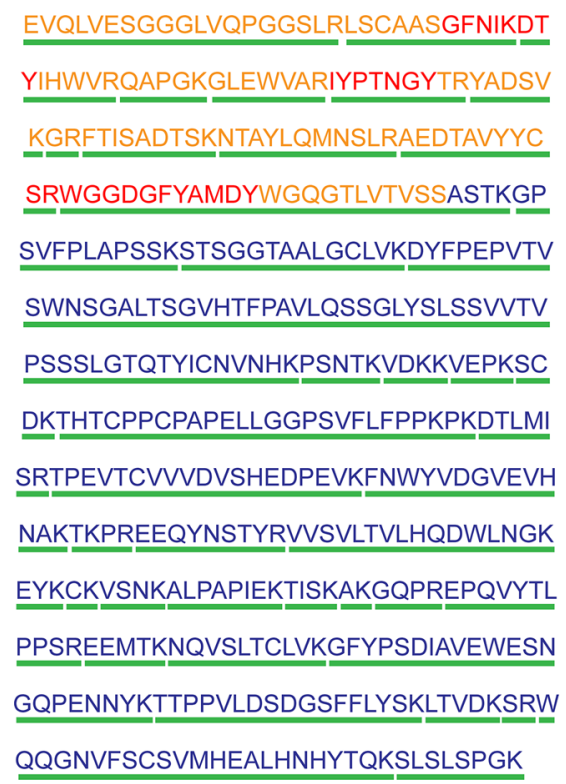

DIQMTQSPSSLSASVGDRVTITCRASQDVNTA VAWYQQKPGKAPKLLIYSASFLYSGVPSRFSG SRSGTDFTLTISSLQPEDFATYYCQQHYTTPPT FGQGTKVEIKRTVAAPSVFIFPPSDEQLKSGTA SVVCLLNNFYPREAKVQWKVDNALQSGNSQE SVTETEQDSKDSTYSLSSTLTLSKADYEKHKVY ACEVTHQGLSSPVTKSFNRGEC

Figure 1. Sequence coverage obtained for trastuzumab by CESI-MS/MS methodology. Experimental conditions: $90 \mathrm{~nL}$ injected (200 fmol). CESIMS/MS spectra recorded on 5600 TripleTOF (AB Sciex, San Francisco, CA). Constant domain (blue), variable domain (orange), and complementarity determining region (red) represent the heavy chain and light chain.

187 MS/MS data analysis: Data obtained from the CESI-MS/MS 188 experiments were analyzed using Peakview software (AB Sciex, 189 San Francisco, CA). Purely tryptic peptides (without 190 miscleavages or PTMs except for cys carbamidomethylation) 191 were determined theoretically from considered $\mathrm{mAb}$ amino acid 192 sequences available through the literature. Additional peptides 193 were identified using Mascot search engine provided by Matrix 194 Science; tryptic cleavage rules were applied. Carbamidomethy195 lation of cysteine $(+57.02 \mathrm{Da})$ and N-deamidation of aspartic/ 196 isoaspartic acid $(+0.985 \mathrm{Da})$ or succinimide intermediate $197(-17.03 \mathrm{Da})$ were selected as variable modifications. 198 Methionine oxidation $(+15.99 \mathrm{Da})$ and $\mathrm{N}$-terminal glutamic 199 acid cyclization $(-17.02 \mathrm{Da})$ were also selected as variable 200 modifications. The mass tolerance allowed for search algorithm 201 identification was set to $\pm 5 \mathrm{ppm}$ for precursor ions and \pm 0.05 $202 \mathrm{Da}$ for fragmentation ions.

\section{RESULTS AND DISCUSSION}

$204 \mathrm{mAbs}$ were characterized in a bottom-up proteomic adapted 205 strategy, and samples were digested by trypsin using an in206 solution digestion protocol. We reported previously the 207 development of a method using sheathless CE-ESI-MS/MS 208 for monoclonal antibody characterization. ${ }^{25}$ In the current work 209 the methodology was significantly modified to improve the 210 level of characterization, especially regarding the amino acid 211 sequence and glycoforms. The digestion protocol was modified 212 to enhance proteolytic digestion efficiency. Additionally, the 213 changes increased the compatibility of the sample's content to 214 capillary zone electrophoresis (CZE) and transient isotacho215 phoresis (t-ITP) while also controlling the matrix effect. The 216 sample preparation was conducted without any desalting 217 treatment to prevent any potential loss of peptides due to 218 either poor or irreversible retention during reverse-phase solid219 phase extraction (SPE). After digestion, the sample was diluted 220 to a final concentration of $2.2 \mu \mathrm{M}$ in ammonium acetate (50 $221 \mathrm{mM}, \mathrm{pH}$ 4.0). Ammonium acetate was chosen as a sample 222 matrix for its compatibility with both ESI-MS and t-ITP. The 223 separation was performed under an electrical field of $210 \mathrm{~V} / \mathrm{cm}$ in a background electrolyte (BGE) composed of $10 \%$ acetic 224 acid. This BGE has two advantages; it presents a rather low 225 conductivity, as it is not a strong acid, and it is fully compatible 226 with the ESI ionization process. mAb digests were analyzed 227 through CESI-MS/MS, and the injection volume corresponded 228 to a quantity of $200 \mathrm{fmol}$ of digested peptides. Peptide 229 identification was performed through a peptide fragment 230 fingerprinting (PFF) strategy where peptides are identified 231 based on their complete molecular mass and fragmentation 232 pattern with a mass accuracy systematically better than 5 ppm. 233

As emphasized in Figure 1, the CESI-MS/MS analysis of the $234 \mathrm{fl}$ $\mathrm{mAb}$ tryptic digest allowed us, in a single injection, to obtain 235 $100 \%$ sequence characterization for both the HC and LC. 236 Furthermore, the full sequence characterization could be 237 performed exclusively through identification of peptides 238 without PTMs or miscleavages. To our knowledge, this is the 239 first time that a protein tryptic digest could be entirely 240 characterized in a single injection in such a manner. As 241 expected, additional peptides exhibiting miscleavages or various 242 PTMs could also be identified during the experiment; they can 243 be used to confirm parts of the AA sequence if necessary. This 244 result was achieved by the use of t-ITP CESI-MS/MS for the 245 method along with the sample preparation which was adapted 246 to allow highly efficient digestion. Additionally, sample 247 preparation enables a complete compatibility with the CE 248 separation conditions. Indeed, sample preparation exploits the 249 electrokinetic separation and ESI ionization to the fullest 250 extent. The same experiment was performed by nanoLC-MS/ 251 MS on trastuzumab digest using the same instrumental settings. 252 Identifications from a single nanoLC-MS/MS analysis did not 253 result in complete sequence coverage (Supporting Information 254 Figure S-1). A simple solution to complete the sequence 255 coverage would be to use a different proteolytic enzyme such as 256 chymotrypsin and concatenate all peptides identified in each 257 digest.

The capacity to characterize, without restrictions, every 259 peptide comprising the digest opens new possibilities for 260 protein primary structure characterization. In particular, the 261 
262 possibility exists to go beyond the DNA sequence usually used 263 for peptide identification and also identify mutations and/or 264 transcription mismatches. This capability is enabled by the low $265 \mathrm{pH}$ (2.2) of the BGE, which induces every peptide to be 266 positively charged in solution. Under this condition, all peptides 267 migrate toward the MS inlet, regardless of their chemical 268 nature, under electrophoresis, as it can be demonstrated by the 269 separation and identification, under the same experimental 270 conditions, of peptides having from 2 to 63 AAs and a large 271 range of isoelectric points (pI). Results point out additional 272 advantages provided by the CESI-MS technique for protein 273 characterization; N-terminal as well as C-terminal parts of the 274 protein could be completely and robustly characterized. 275 Moreover in this case, the N-terminal parts known as the 276 variable domain of the antibody are involved in antibody277 antigen recognition and require a high level of characterization. 278 Tandem MS (MS/MS), through gas-phase fragmentation of 279 tryptic peptides, allows precise identification of the AA order of 280 a peptide depending on the spectra quality. ${ }^{26}$ Results 281 demonstrated the capacity of the CESI-MS technique to obtain 282 almost all $\mathrm{y} / \mathrm{b}$ ions of peptides from $\mathrm{mAb}$ variable domains and 283 even for trastuzumab in its totality. Over the whole protein, 284 systematically more than $70 \%$ of the $y / b$ fragment ions could 285 be obtained during the experiment and more than $90 \%$ in the 286 case of trastuzumab (Table 1), depending largely on the size of

Table 1. Summarized Results Obtained for a Single Analysis of Each Antibody Studied Using CESI-MS/MS Analysis, Showing the Robustness of the Methodology Developed and the Extension of the Primary Structure Characterization

\begin{tabular}{|c|c|c|c|c|}
\hline & trastuzumab & cetuximab & $\begin{array}{c}\mathrm{mAb} \text { in-dev } \\
\# 1\end{array}$ & $\begin{array}{c}\mathrm{mAb} \text { in-dev } \\
\# 2\end{array}$ \\
\hline sequence coverage & $100 \%$ & $100 \%$ & $100 \%$ & $100 \%$ \\
\hline$\%$ MS2 y/b ions & $>90 \%$ & $>70 \%$ & $>90 \%$ & $>70 \%$ \\
\hline $\begin{array}{l}\text { identified } \\
\text { glycosylations }\end{array}$ & 15 & 15 & 10 & 16 \\
\hline Other PTM Hotspots & & & & \\
\hline $\begin{array}{l}\text { glutamic acid } \\
\text { cyclization }\end{array}$ & $1 / 1$ & $1 / 1$ & $1 / 1$ & $1 / 1$ \\
\hline methionine oxidation & $2 / 2$ & $0 / 0$ & $2 / 2$ & $0 / 0$ \\
\hline $\begin{array}{l}\text { asparagine } \\
\text { deamidation }\end{array}$ & $4 / 4$ & $4 / 4$ & $2 / 2$ & $4 / 4$ \\
\hline $\begin{array}{l}\text { aspartic acid } \\
\text { isomerization }\end{array}$ & $6 / 6$ & $2 / 2$ & $3 / 3$ & $2 / 2$ \\
\hline
\end{tabular}

287 the tryptic peptides generated. The $\mathrm{y}$ and $\mathrm{b}$ ions are generated 288 by peptide fragmentation in collision-induced dissociation 289 (CID) in MS/MS. ${ }^{27}$ Peptide identifications are partially based 290 on those fragment ions. The possibility to detect nearly all of 291 the fragment ions allows, on one hand, increased confidence in 292 the identification. On the other hand, fragment ions give 293 precious information about the precise succession order of AAs 294 along the sequence and allow determination of the exact AAs 295 experiencing chemical modifications. This capability could be 296 confirmed for both the HC and LC of the four different mAbs 297 studied (trastuzumab, cetuximab, mab 1, and mab 2). 298 Additionally, three different digestions were characterized for 299 each sample and considered as technical replicates, allowing us 300 to obtain similar results and proving the robustness of the 301 designed methodology. MS/MS results describe the superior 302 spectra quality obtained while coupling CE to MS by means of 303 the CESI interface. Spectra quality is a direct consequence of 304 the ionization efficiency which directly impacts the achievable sensitivity and signal/noise ratio. In the case of the CESI 305 interface, the ability to generate a very stable spray at quite low 306 flow rates enables robust operation in the nanoESI regime. 307 Intrinsic characteristics of the CESI interface have a key role in 308 the ionization yield of the interface. ${ }^{28}$ Briefly, in nanoESI, 309 smaller droplets are initially formed, favoring Rayleigh division 310 but also a desolvation process and finally resulting in readily 311 improved ionization and signal/noise ratio compared to 312 standard ESI. ${ }^{29}$

313

mAbs are glycosylated proteins, and those glycans are 314 naturally incorporated in the protein during secretion into the 315 extracellular environment. ${ }^{30}$ Glycosylation has been implicated 316 in $\mathrm{mAb}$ safety and pharmacokinetics/pharmacodynamics (PK/ 317 $\mathrm{PD}$ ) and is one of the main sources of heterogeneity among 318 this type of protein. Therefore, extensive characterization in 319 terms of structure and relative abundance are mandatory. 320 Concomitantly to primary sequence characterization, using the 321 same CESI-MS/MS data, in-depth characterization of glyco- 322 sylation was possible. For example, in the case of trastuzumab, 323 15 different glycoforms were identified, demonstrating the 324 outstanding sensitivity of the CESI-MS method (Figure 2). $325 \mathrm{f} 2$ Glycopeptides were identified based on accurate mass measure- 326 ment in MS1 provided by high resolution MS (sub $2 \mathrm{ppm}$ ) and, 327 additionally, fragmentation spectra. Indeed, MS/MS spectra 328 exhibited the fragmentation of glycans present on the 329 glycopeptide, giving structural information on the glycans 330 along with reinforcing the confidence of the identification. 331 Furthermore, the electropherogram obtained showed partial 332 separation of the different glycopeptides, demonstrating the 333 benefit of using CE as the separating technique for this type of 334 characterization. As displayed in Figure 2, particular glycopep- 335 tides having a difference of one galactose (meaning a mass 336 difference of $162 \mathrm{Da}$ ) could be baseline separated. The capacity 337 to separate peptides having such small differences is clearly 338 interesting because they tend to compete against each other 339 during the ionization process, potentially interfering with 340 relative quantification. Therefore, their separation participates 341 to ease their ionization, imparting a rare sensitivity with regard 342 to glycosylation characterization with the CESI-MS/MS 343 methodology developed. Such sensitivity could be achieved 344 while the entire peptide digest mixture was characterized 345 without glycan release followed by extraction which is 346 commonly performed in glycan analysis by MS. ${ }^{31}$ Cetuximab 347 contains a second $\mathrm{N}$-glycosylation site on the $\mathrm{HC}$ : one is 348 located in the $\mathrm{Fc} / 2$ domain $\left(\mathrm{Asn}^{299}\right)$ similarly to trastuzumab 349 while the second one is located in the Fd domain on Asn ${ }^{88} .32350$ The CESI-MS/MS experiments on cetuximab indicated the 351 two different sites, and each glycosylation site could be 352 precisely located based on the CESI-MS/MS data. Additionally, 353 structural glycan characterization as well as relative quantifica- 354 tion could both be established independently for each site in 355 the same experiment.

356

Additional PTMs were also analyzed in the same run. For 357 example, the trastuzumab $\mathrm{HC} \mathrm{N}$-terminal extremity contains a 358 glutamic acid which can undergo partial cyclization leading to 359 pyroglutamic acid. ${ }^{20}$ The $\mathrm{m} / z$ ratios corresponding to the 360 native $\mathrm{N}$-terminal peptide and the pyroglutamic acid variant 361 migrate as two different peaks separated by several minutes. 362 This result can be explained by the fact that glutamic acid 363 cyclization entails for the AA a mass loss of $17.02 \mathrm{Da}$. As CE 364 separates compounds on the basis of their size and charge state 365 in solution, this PTM involves a significant modification of the 366 electrophoretic mobility. 


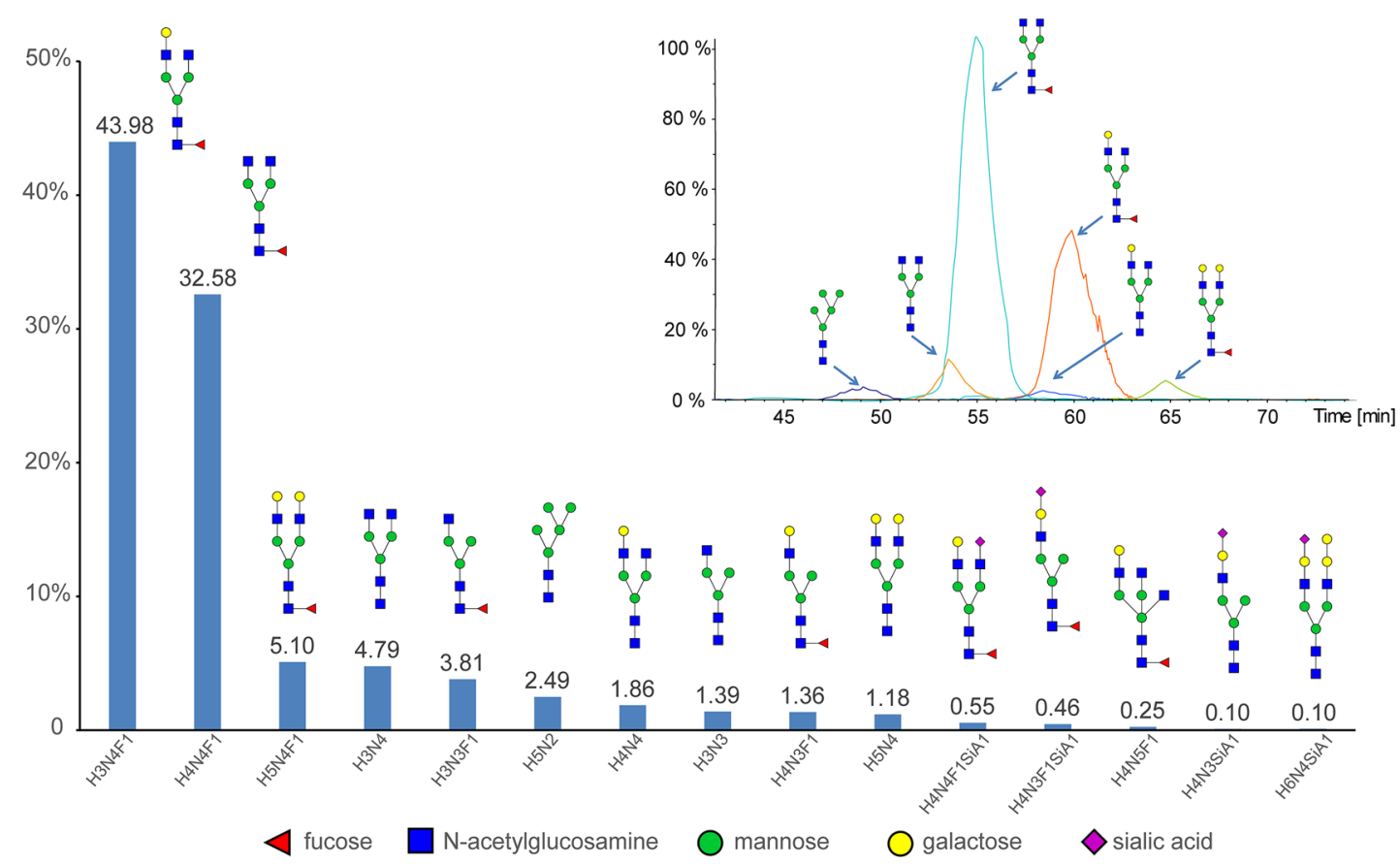

Figure 2. Glycoform determination obtained for trastuzumab using the CESI-MS/MS method in a single analysis (left-hand side). Extracted ion electropherogram (EIE) corresponding to the $\mathrm{m} / \mathrm{z}$ of the most abundant glycoforms, illustrating the separation selectivity obtained with CE regarding $\mathrm{mAb}$ glycopeptides (right-hand side).
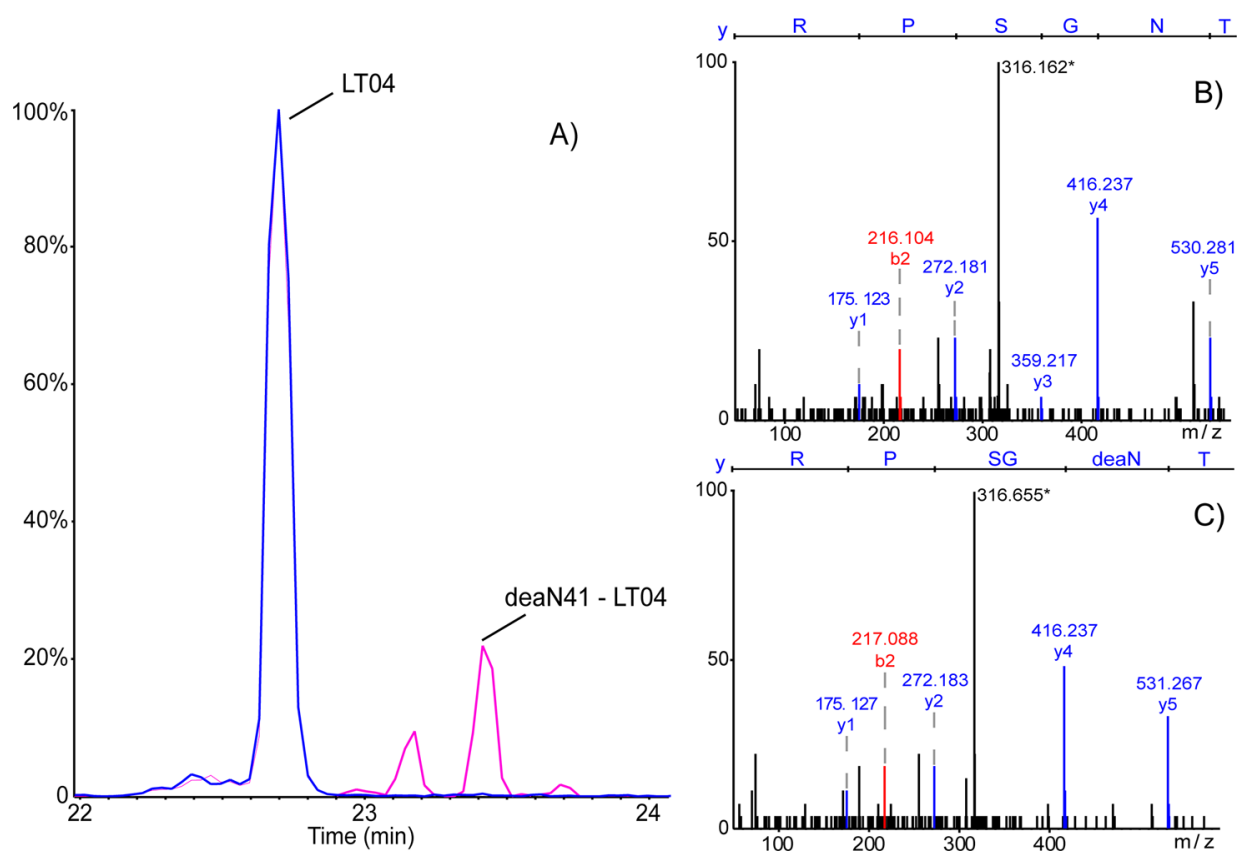

Figure 3. (A) EIE corresponding to the $m / z$ of peptide LT04 (light chain, position 40-45) and LT06 with deamidated Asp41. Deconvoluted MS/ MS spectra corresponding to (B) peptide LT04 and (C) LT04 deamidated Asp41 (deamidation represented by deaN).

368 Another common microvariant is methionine oxidation. This 369 modification implies for the peptide a mass increase of 15.99 370 Da while the charge density remains the same. In a similar way 371 as previously, the same CESI-MS/MS data highlight the 372 capacity of $\mathrm{CE}$ to separate the modified peptide undergoing 373 methionine oxidation from the native peptide (Supporting 374 Information Figure S-2). Those results open perspectives for 375 improved relative quantification regarding the level of 376 occurrence of those modifications similarly to glycosylation 377 characterization.
Deamidation is associated with the removal of the amide 378 group present on the side chain of asparagine (Asn) and, to a 379 lesser extent, of glutamine (Gln) residues. ${ }^{33}$ These modifica- 380 tions are observed by separation methods such as isoelectric 381 focusing (IEF) and cationic exchange chromatography (CEX) 382 in combination with offline MS methods. In contrast, the CESI- 383 MS/MS method afforded complete separation between the 384 parent and the degraded peptide (Figure 3). That characteristic $385 \mathrm{f} 3$ in separation could be confirmed for every deamidation hot- 386 spot identified on both trastuzumab and cetuximab (four 387 


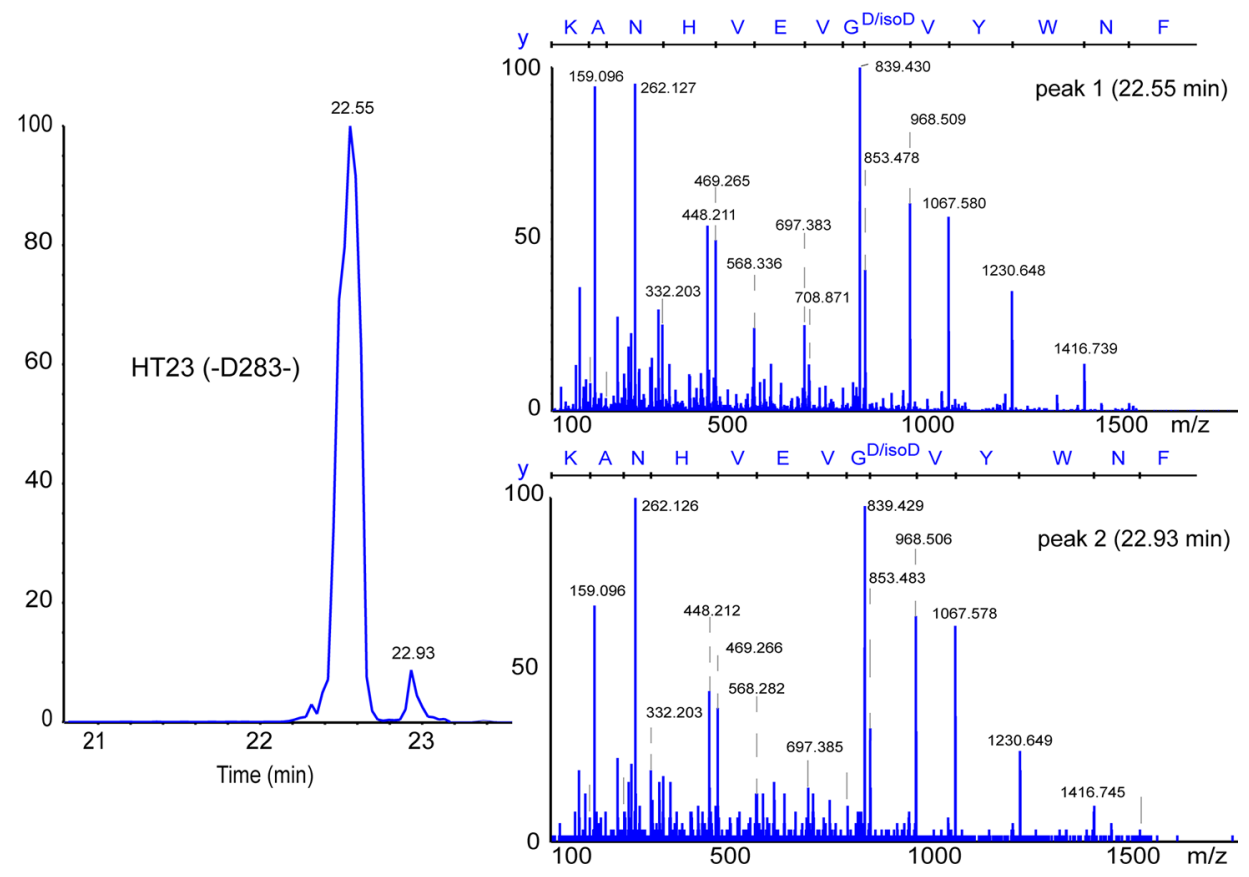

Figure 4. EIE corresponding to $\mathrm{m} / z$ for digested peptide HT23 (heavy chain; position 278-291) experiencing aspartic acid isomerization. Raw MS/ MS spectra for both peaks (right-hand side) demonstrated the same fragmentation pattern in addition to precursor $m / z$ and charge state values.

388 different sites each). The ability to separate those modified 389 peptides is particularly important. Deamidation involves a loss 390 of only $0.98 \mathrm{Da}$; such a small difference would lead, during the 391 ionization process, to competition, lowering the sensitivity of 392 the MS signal in the case that both peptides could not be 393 separated. That appears to be quite relevant, as the deamidation 394 sites on the studied mAbs exhibited a low level of modification 395 usually below 5\%, urging the necessity to prevent ionization 396 competition. The excellent separation provided by CE enables, 397 in the case of this characterization, the best sensitivity for both 398 peptides. One direct consequence is that the fragmentation 399 spectra quality was significantly improved, allowing precise 400 location of the modified AA even if other Asn or Gln were 401 present in the peptide.

402 The last considered PTM is aspartic acid isomerization; this 403 modification is particularly difficult to characterize. Indeed, the 404 change of conformation of aspartic acid (Asp) could not induce 405 a significant variation of affinity toward the reverse stationary 406 phase and requires particular analytical methodologies giving 407 access only to a specified aspect of the protein. ${ }^{33-35}$ 408 Furthermore, the conformation change does not induce a 409 change in the mass of the peptide; thus, ESI-MS using hybrid 410 analyzers such as a quadrupole-time-of-flight (Q-TOF) does 411 not allow a determination of potential Asp isomerization. From 412 the CESI-MS/MS data, extraction of the $m / z$ ratio correspond413 ing to a peptide potentially presenting Asp isomerization 414 systematically exhibited two consecutive peaks as shown in in 415 Figure 4. The important acquisition rate capacity provided by 416 MS therefore enabled us, from the CESI-MS/MS data, to 417 obtain the fragmentation spectra for both peaks. From the 418 fragmentation pattern, MS/MS spectra presented in Figure 4 419 unambiguously proved that the two peaks correspond to the 420 same peptides. Fragmentation is obtained inside the MSCID; in 421 this fragmentation mode the energy conveyed to neutral 422 particles (usually $\mathrm{N}_{2}$ or Ar) is limited to a few tenths of an 423 electron volt $(\mathrm{eV})$. Such energy levels allow the activation of 424 the fragmentation of the peptide backbone, enabling the detection of specific $\mathrm{b}$ and $\mathrm{y}$ fragments ions. ${ }^{36}$ In the context of 425 this study, two consecutive peaks leading to the same 426 fragmentation spectrum suggest that those CE conditions 427 enable the separation of the same peptide having different Asp 428 isomers. From a theoretical aspect, electrophoretic mobility is 429 significantly influenced by the hydrodynamic radius of the 430 molecule. Two similar peptides with the same AA sequence 431 containing different aspartic acid isomers should be differently 432 oriented. This would most likely induce a difference in their 433 respective hydrodynamic radius, therefore implying a difference 434 of electrophoretic mobilities between them. Also the different 435 potential Asp isomerization sites studied, on both samples, 436 exhibited the same behavior while peptides having no Asp did 437 not present this characteristic, reinforcing the assertion on 438 separation based on Asp isomerization.

439

To validate with certainty the capacity of the developed CE 440 method to separate peptides with regard to Asp isomerization, 441 two peptides were specially synthesized. Those peptides, 442 composed of 20 AAs, have exactly the same AA sequence 443 and contain one Asp, each synthetic peptide bearing a different 444 Asp isomer. As emphasized in Supporting Information Figure 445 S-3, several samples composed of a mixture of both synthetic 446 peptides in different ratios were analyzed using the same t-ITP- 447 CESI-MS/MS conditions as in the $\mathrm{mAb}$ characterization. 448 Results obtained for the different mixture ratios exhibit two 449 consecutive peaks for the $\mathrm{m} / z$ ratios corresponding to the 450 synthetic peptide. On the contrary, when only a single peptide 451 is injected, the extracted ion electropherogram (EIE) showed 452 only one peak. To reinforce the result, peak heights illustrate 453 relatively the evolution in proportion of one peptide to the 454 other. These results demonstrate without ambiguity the 455 selectivity of the separation in the case of a peptide 456 experiencing Asp isomerization. These results further empha- 457 size the relevance of using CE separation for protein primary 458 structure by MS. It indeed allows the discrimination of peptides 459 having Asp isomerization in a robust manner, thereby further 460 
461 enriching the information that can be obtained by MS on a 462 given protein molecule.

\section{CONCLUSION}

464 To summarize, we report here the use of t-ITP-CESI-MS/MS 465 for the characterization of four different therapeutic mAbs. The 466 instrumental components used include in particular a CE-ESI467 MS interface which has been recently developed. Using a single 468 injection, we were able to characterize the primary structure of 469 those antibodies in a robust manner at an unprecedented level. 470 We managed to obtain the complete AA sequence character471 ization while only relying on tryptic peptide without 472 miscleavages or exogenous modifications. It is the first time 473 that this level of characterization has been achieved in a single 474 injection/run, suggesting new approaches for bottom-up 475 proteomics in particular. Simultaneously to the AA sequencing, 476 PTMs including glycosylation were also characterized. Results 477 highlighted the benefit of using electrophoretic separation in 478 complement to chromatographic separation which is conven479 tionally applied in this type of study. CE separation selectivity 480 showed the ability to separate peptides having only minor 481 differences while the sensitivity provided by CESI-MS led to 482 the improvement of the MS/MS characterization. Indeed, the 483 opportunity to separate peptides having only an isomerization 484 of one AA or a difference of $0.98 \mathrm{Da}$ enables the ability to 485 cancel ionization competition between the different peptides 486 and explains the capacity of the CESI-MS/MS methodology to 487 characterize, in the same experiment, the intact and the 488 modified peptide. Similarly, CE proved through MS to ease 489 primary structure characterization, as it was possible to detect 490 aspartic acid isomerization on several peptides from the same 491 analysis along with its other attributes. Glycosylations were also 492 characterized from the same experiment; thus, 15 different 493 glycans could be characterized for trastuzumab, showing that 494 using CESI-MS improved the sensitivity. Note that no glycan 495 release was necessary, reducing the sample treatment and the 496 necessity to use different experimental conditions to character497 ize glycosylation along with the other characteristics of the 498 primary structure of the protein. Finally this experiment could 499 be achieved by injecting a quantity of sample corresponding to $500200 \mathrm{fmol}$ of digested peptide, illustrating the suitability of the 501 CESI-MS/MS method for small amounts of sample. The CESI$502 \mathrm{MS} / \mathrm{MS}$ data reported here indicate that electrophoretic 503 separation, combined with the highly efficient CESI interface, 504 becomes a viable alternative to LC-ESI-MS/MS for innovative 505 approaches in MS proteomics such as identifying AA mutations 506 or transcription mismatches.

\section{ASSOCIATED CONTENT}

\section{S Supporting Information}

509 Additional information as noted in the text. This material is 510 available free of charge via the Internet at http://pubs.acs.org.

\section{AUTHOR INFORMATION}

\section{Corresponding Author}

513 *E-mail: yfrancois@unistra.fr.

\section{Notes}

515 The authors declare no competing financial interest.

\section{ACKNOWLEDGMENTS}

517 The authors thank Sciex Separations Inc. for lending a CESI 518 prototype and Dr. M. Anselme from Sciex Separations Inc. for his support. LSMIS thanks Philippe Hammann, Lauriane Kuhn, 519 and Johana Chicher (Institut de Biologie Moléculaire et 520 Cellulaire, Strasbourg, France) for giving access to their mass 521 spectrometer. The authors acknowledge Dr. Joseph Vlasak 522 (Merck, West Point, PA) for critical reading of the manuscript. 523 The authors also express their gratitude to M. Biacchi (LSMIS, 524 Strasbourg, France), Dr. E. Wagner-Rousset, Dr. D. Ayoub, M. 525 C. Janin-Bussat, and O. Colas (Centre d'immunologie Pierre 526 Fabre, St Julien en Genevois, France) for helpful discussions 527 about antibody structural characterization.

528

\section{REFERENCES}

(1) Jorgenson, J. W.; Lukacs, K. D. Anal. Chem. 1981, 53, 1298- 530 1302.

(2) Jorgenson, J.; Lukacs, K. Science 1983, 222, 266-272.

(3) Hjertén, S. J. Chromatogr., A 1983, 270, 1-6. 533

(4) Tiselius, A. U. u. The moving boundary method of studying the 534 electrophoresis of proteins; Almqvist \& Wiksell: Uppsala, 1930.

(5) Longsworth, L. G.; MacInnes, D. A. Chem. Rev. 1939, 24, 271- 536 287.

(6) Mokaddem, M.; Gareil, P.; Belgaied, J. E.; Varenne, A. 538 Electrophoresis 2008, 29, 1957-1964.

(7) Mokaddem, M.; Gareil, P.; Belgaied, J. E.; Varenne, A. 540 Electrophoresis 2009, 30, 1692-1697.

(8) Fenn, J. B.; Mann, M.; Meng, C. K.; Wong, S. F.; Whitehouse, C. 542 M. Science 1989, 246, 64-71.

(9) Tito, M. A.; Tars, K.; Valegard, K.; Hajdu, J.; Robinson, C. V. J. 544 Am. Chem. Soc. 2000, 122, 3550-3551.

(10) Schagger, H.; Vonjagow, G. Anal Biochem 1991, 199, 223-231. 546

(11) Klepárník, K.; Bocček, P. Chem. Rev. 2007, 107, 5279-5317. 547

(12) Salas-Solano, O.; Carrilho, E.; Kotler, L.; Miller, A. W.; 548 Goetzinger, W.; Sosic, Z.; Karger, B. L. Anal. Chem. 1998, 70, 3996- 549 4003.

(13) Berk, A. J.; Sharp, P. A. Cell 1977, 12, 721-732.

(14) Boodram, S. N.; McCann, L. C.; Organ, M. G.; Johnson, P. E. 552 Anal. Biochem. 2013, 442, 231-236.

(15) Busnel, J.-M.; Schoenmaker, B.; Ramautar, R.; Carrasco- 554 Pancorbo, A.; Ratnayake, C.; Feitelson, J. S.; Chapman, J. D.; 555 Deelder, A. M.; Mayboroda, O. A. Anal. Chem. 2010, 82, 9476-9483. 556

(16) Moini, M. Anal. Chem. 2007, 79, 4241-4246. 557

(17) Zhu, G.; Sun, L.; Yan, X.; Dovichi, N. J. Anal. Chem. 2013, 85, 558 2569-2573.

(18) Wang, Y.; Fonslow, B. R.; Wong, C. C. L.; Nakorchevsky, A.; 560 Yates, J. R. Anal. Chem. 2012, 84, 8505-8513.

(19) Malá, Z.; Gebauer, P.; Boček, P. Electrophoresis 2013, 34, 19-28. 562

(20) Beck, A.; Wagner-Rousset, E.; Ayoub, D.; Van Dorsselaer, A.; 563 Sanglier-Cianferani, S. Anal. Chem. 2013, 85, 715-736. 564

(21) Hudis, C. A. N. Engl. J. Med. 2007, 357, 39-51.

(22) Ayoub, D.; Jabs, W.; Resemann, A.; Evers, W.; Evans, C.; Main, 566 L.; Baessmann, C.; Wagner-Rousset, E.; Suckau, D.; Beck, A. mAbs 567 2013, 5, 699-710.

(23) Li, S.; Schmitz, K. R.; Jeffrey, P. D.; Wiltzius, J. J. W.; Kussie, P.; 569 Ferguson, K. M. Cancer Cell 2005, 7, 301-311. 570

(24) Walsh, G.; Jefferis, R. Nat. Biotechnol. 2006, 24, 1241-1252. 571

(25) Gahoual, R.; Burr, A.; Busnel, J.-M.; Kuhn, L.; Hammann, P.; 572 Beck, A.; François, Y.-N.; Leize-Wagner, E. $m A$ bs 2013, 5, 479-490. 573

(26) Domon, B.; Aebersold, R. Science 2006, 312, 212-217. 574

(27) Paizs, B.; Suhai, S. Mass Spectrom. Rev. 2005, 24, 508-548. 575

(28) Gahoual, R.; Busnel, J.-M.; Wolff, P.; François, Y.; Leize- 576 Wagner, E. Anal. Bioanal. Chem. 2014, 406, 1029-1038. 577

(29) Wilm, M. S.; Mann, M. Int. J. Mass Spectrom. Ion Processes 1994, 578 136, 167-180.

(30) Beck, A.; Wagner-Rousset, E.; Bussat, M. C.; Lokteff, M.; 580 Klinguer-Hamour, C.; Haeuw, J. F.; Goetsch, L.; Wurch, T.; Van 581 Dorsselaer, A.; Corvaia, N. Curr. Pharm. Biotechnol. 2008, 9, 482-501. 582

(31) Wagner-Rousset, E.; Bednarczyk, A.; Bussat, M.-C.; Colas, O.; 583 Corvaïa, N.; Schaeffer, C.; Van Dorsselaer, A.; Beck, A. J. Chromatogr., 584 B 2008, 872, 23-37. 
586 (32) Beck, A.; Sanglier-Cianférani, S.; Van Dorsselaer, A. Anal. Chem. 587 2012, 84, 4637-4646.

588 (33) Vlasak, J.; Bussat, M. C.; Wang, S.; Wagner-Rousset, E.; 589 Schaefer, M.; Klinguer-Hamour, C.; Kirchmeier, M.; Corvaïa, N.; 590 Ionescu, R.; Beck, A. Anal. Biochem. 2009, 392, 145-154.

591 (34) Kern, W.; Mende, R.; Denefeld, B.; Sackewitz, M.; Chelius, D. J. 592 Chromatogr., B 2014, 955-956, 26-33.

593 (35) Zhang, J.; Yip, H.; Katta, V. Anal. Biochem. 2011, 410, 234-243.

594 (36) Mitchell Wells, J.; McLuckey, S. A. In Methods in Enzymology; 595 Burlingame, A. L., Ed.; Academic Press: New York, 2005; pp 148-185. 